\title{
Local-look navigator gated and cardiac triggered echo-planar spectroscopic imaging of the heart
}

\author{
Kilian Weiss ${ }^{1 *}$, Nicola Martini ${ }^{2}$, Peter Boesiger ${ }^{1}$, Sebastian Kozerke ${ }^{1}$ \\ From 2011 SCMR/Euro CMR Joint Scientific Sessions \\ Nice, France. 3-6 February 2011
}

\section{Introduction}

Single-voxel proton magnetic resonance spectroscopy has been shown to be a promising tool for assessing creatine [1] and myocardial triglycerides in humans [2, $3,4]$. A focus of interest is the correlation between triglyceride content in the myocardium and cardiac dysfunction [5]. While spectral information from a single volume is sufficient when alterations with global effects on the heart are studied, a demand for higher and flexible spatial resolution exists when probing local changes. The objective of the current work was to implement a navigated local-look Echo-Planar Spectroscopic Imaging (EPSI) sequence for assessment of triglyceride and creatine content in the myocardium in vivo.

\section{Methods}

Local-look navigator gated spin-echo EPSI (Figure 1) was implemented on a 1.5T Philips Achieva system (Philips

Healthcare, Best, The Netherlands). Field-of-excitation (FOX) reduction was based on an optimized selective excitation pulse in phase encoding direction (Figure 2). Pencil-beam navigator echoes were integrated for respiratory gating purposes. Sequence parameters were as follows: echo time: $12 \mathrm{~ms}$, FOV: $300 \times 150 \mathrm{~mm}^{2}$, FOX: 65 to $85 \mathrm{~mm}$, spatial resolution: $3 \times 3 \mathrm{~mm}^{2}$, slice thickness: $15 \mathrm{~mm}$, spectral resolution: $4.1 \mathrm{~Hz}, 8$ signal averages, Ernst angle: $\sim 120$ deg, cardiac trigger delay: $\sim 320 \mathrm{~ms}, 5-$ element cardiac coil array for signal reception. Watersuppressed and unsuppressed EPSI data were acquired in healthy volunteers during free breathing in an average scan time of 2:30 min per average depending on heart rate and respiratory navigator efficiency. For comparison single voxel data were acquired using the navigator gated and cardiac triggered PRESS sequence. The single voxel was placed in the septum to avoid signal contamination from epicardial fat (Figure 2).

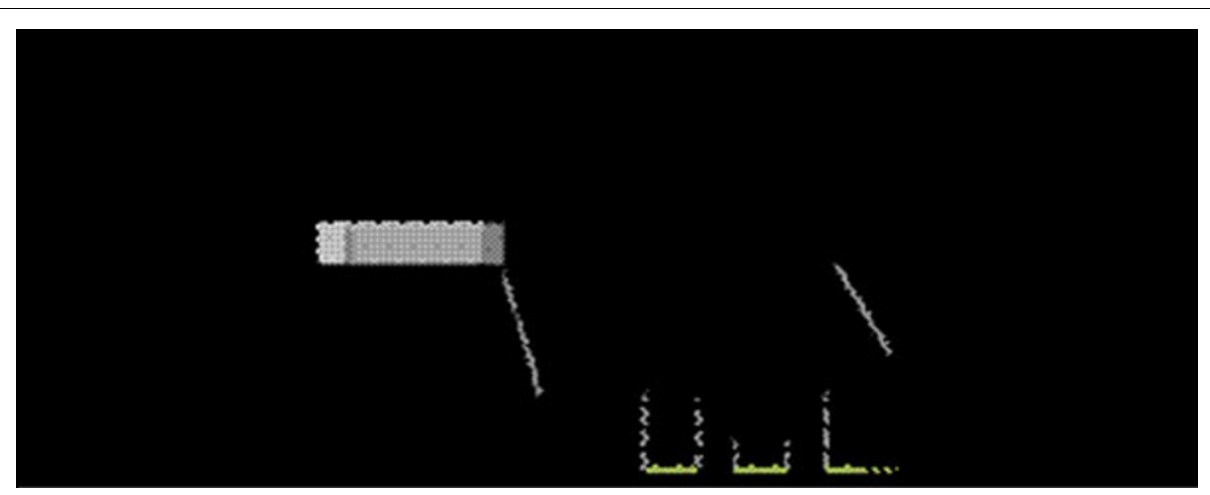

Figure 1 Schematic of the local look navigator gated EPSI sequence a) using echo planar readouts b).

${ }^{1}$ University and ETH Zurich, Zurich, Switzerland

Full list of author information is available at the end of the article

(C) 2011 Weiss et al; licensee BioMed Central Ltd. This is an open access article distributed under the terms of the Creative Commons 


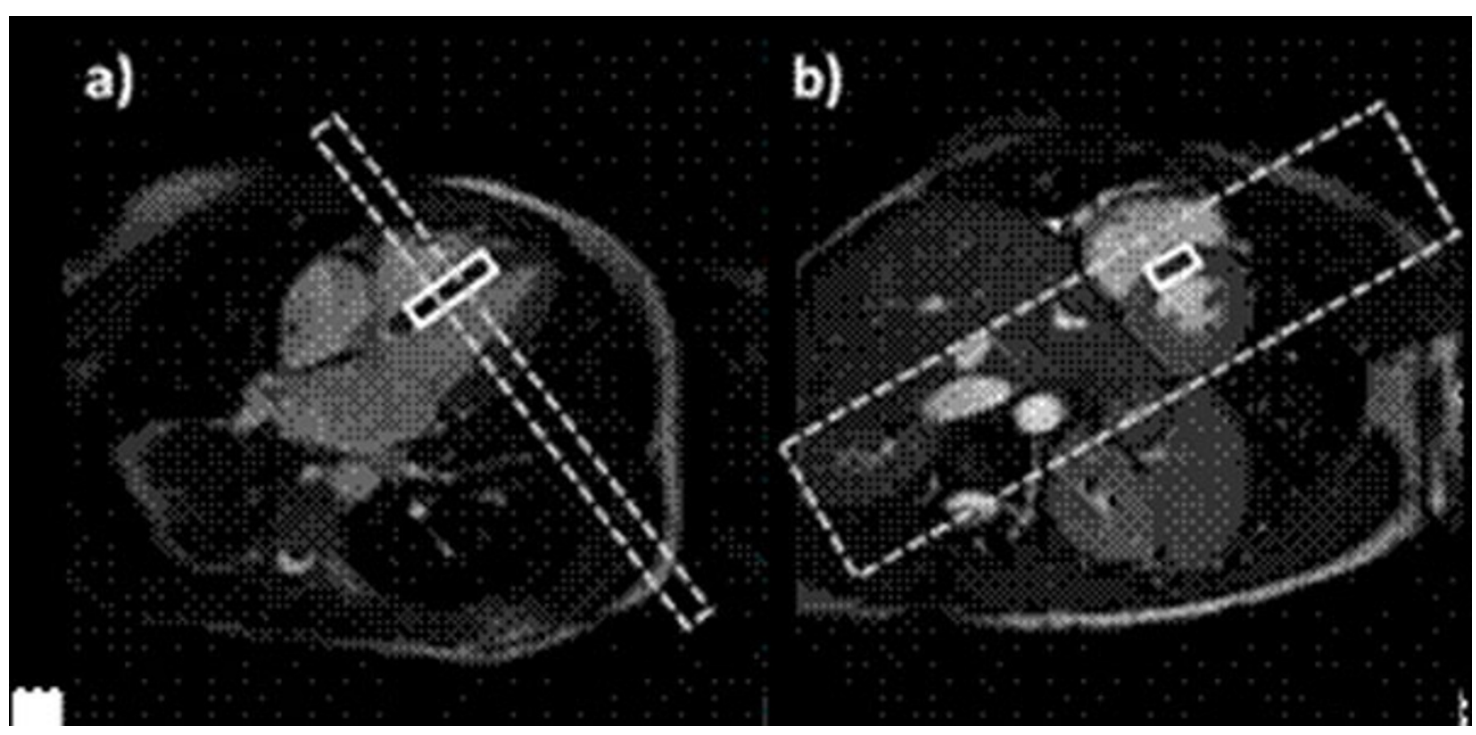

Figure 2 Position of the single voxel (solid line) and the FOX of the EPSI scans (dashed line). (a) Four-chamber view. (b) Short axis view.

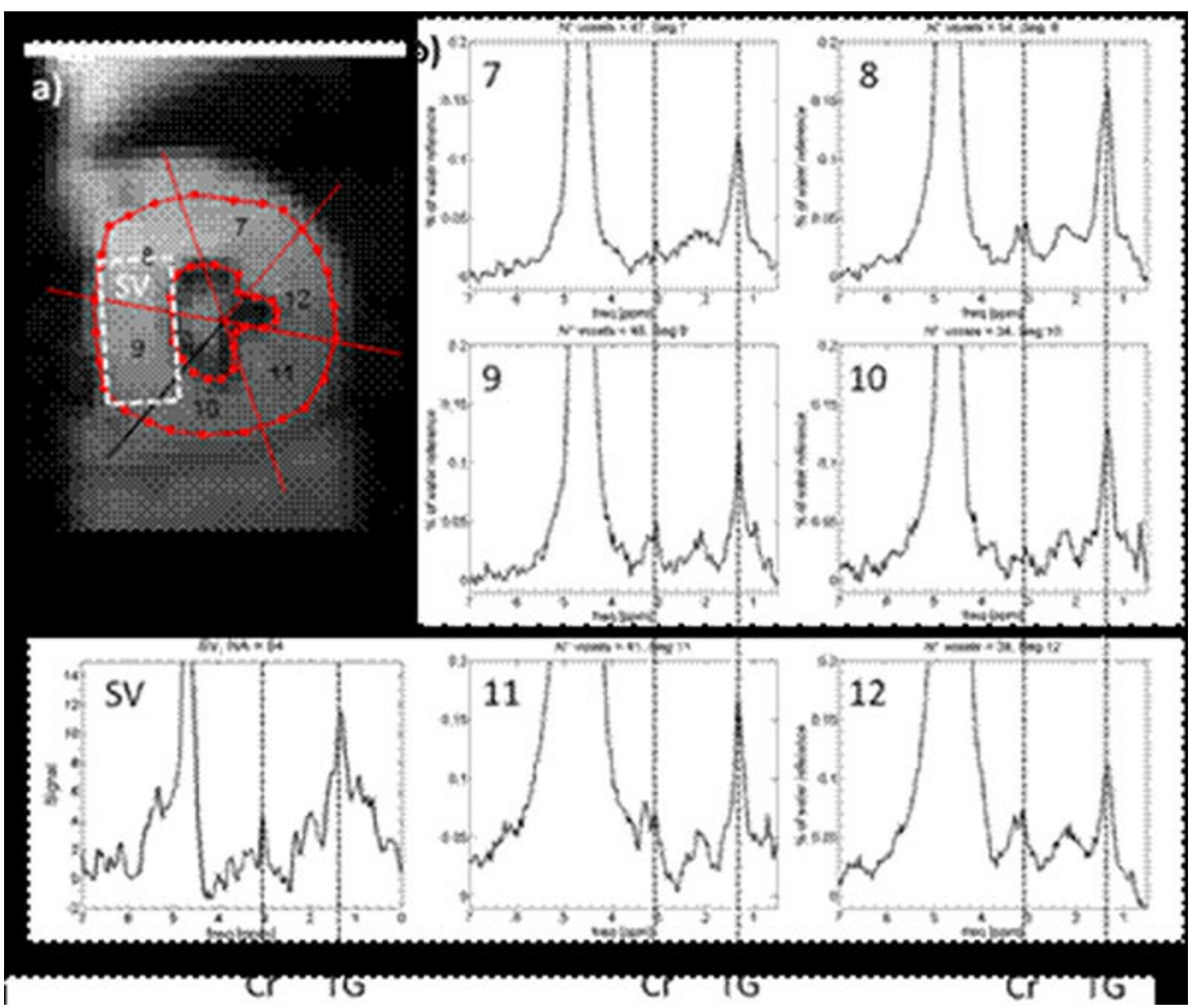

Figure 3 a) Single voxel (SV) and EPCI regions of interst indicated in the EPSI-reference scan. b) Spectra from the regions of interest indicated in a). In all spectra the triglyceride resonance at $1.3 \mathrm{ppm}(\mathrm{TG})$ and the creatine resonance at $3.01 \mathrm{ppm}(\mathrm{Cr})$ can clearly be seen. 


\section{Results}

EPSI and single voxel spectra are shown in Figure 3. Beside spectra from a region of interest located in the septal wall, spectra from six regions of interest from the mid-cavity are shown for the EPSI scans. In all spectra resonances from triglycerides and creatine are visible.

\section{Discussion}

It has been demonstrated that local look navigator-gated and cardiac triggered spin echo EPSI can be used to assess distributions of myocardial triglyceride and creatine resonances during free-breathing acquisitions. Compared to single voxel techniques the EPSI method provides spectra from different regions of the myocardium. In future work higher $\mathrm{B}_{0}$ fields like $3 \mathrm{~T}$ could be used to increase signal-to-noise ratios, to especially enhance the relatively weak signal of creatine.

\section{Author details}

${ }^{1}$ University and ETH Zurich, Zurich, Switzerland. ${ }^{2}$ Fandazione G. Monasterio

CNR-Regione Toscana, Massa, Italy.

Published: 2 February 2011

doi:10.1186/1532-429X-13-S1-078

Cite this article as: Weiss et al:: Local-look navigator gated and cardiac triggered echo-planar spectroscopic imaging of the heart. Journal of

Cardiovascular Magnetic Resonance 2011 13(Suppl 1):078.

Submit your next manuscript to BioMed Central and take full advantage of:

- Convenient online submission

- Thorough peer review

- No space constraints or color figure charges

- Immediate publication on acceptance

- Inclusion in PubMed, CAS, Scopus and Google Scholar

- Research which is freely available for redistribution

Submit your manuscript at www.biomedcentral.com/submit 